\title{
A eficácia incompleta das normas constitucionais: desfazendo um mal- entendido sobre o parâmetro normativo das omissões inconstitucionais
}

\author{
The incomplete effectiveness of constitutional rules: undoing a misunderstanding about \\ the normative framework of unconstitutional omissions
}

\section{George Marmelstein*}

\begin{abstract}
RESUMO: A dogmática constitucional sempre repete a ideia de que o parâmetro normativo capaz de justificar o controle das omissões inconstitucionais deve envolver necessariamente uma norma de eficácia limitada, que, na formulação canônica de José Afonso da Silva, é aquela norma constitucional cuja eficácia plena depende de uma regulamentação posterior. Neste artigo, demonstra-se o equívoco de referida afirmação para concluir que, em determinadas circunstâncias, as chamadas normas de eficácia plena ou contida também podem funcionar como parâmetro normativo para o controle da inconstitucionalidade por omissão.
\end{abstract}

PAlAVRAS-CHAVE: Constitucional; Controle de Constitucionalidade por Omissão; Omissão Inconstitucional; Normas de Eficácia Plena, Contida e Limitada.

ABSTRACT: The Brazilian constitutionalists usually reproduce the ideia that the normative framework able to justify judicial review of state inaction (unconstitutionality by omission) must necessarily involve a special type of constitutional rule called "limited effectiveness" ("norma de eficácia limitada"). That type of rule, as explained José Afonso da Silva, can be described as a constitutional provision whose full effectiveness depends on a supplementary regulation. In this paper, it will be demonstrated the misconception of this ideia. In certain circumstances, others types of rules, such as the ones contained or plain effect, may also be used as a normative framework for judicial review of state inaction (unconstitutionality by omission).

KEYWORDS: Constitutional; Judicial Review; State Inaction; Unconstitutionality by Omission; Effectiveness of Constitutional Norms.

\section{INTRODUÇÃO}

Há certo consenso na dogmática constitucional de que o parâmetro normativo capaz de ensejar a inconstitucionalidade por omissão deve envolver necessariamente uma norma de eficácia limitada. Essa ideia é repetida continuamente, tanto em manuais

\footnotetext{
* Doutor em Direito pela Universidade de Coimbra, mestre em Direito Constitucional pela Universidade Federal do Ceará, professor de Direito Constitucional, juiz federal no Ceará. E-mail: georgemlima@yahoo.com.br.

Data de recebimento do artigo: 18/01/2016 - Data de avaliação: 29/01/2016 e 01/02/2016.
} 
A eficácia incompleta das normas constitucionais: desfazendo um mal-entendido sobre o parâmetro normativo das omissões constitucionais

jurídicos quanto em obras específicas sobre as omissões inconstitucionais, desde os primeiros estudos da constituição de 1988 até as análises mais recentes ${ }^{1}$.

1 A título de exemplos: "Não é a falta de atuação administrativa que possibilita a impetração do mandado de injunção, mas a falta de norma regulamentadora de normas constitucionais de eficácia limitada. (Normas constitucionais de eficácia limitada, justamente porque não reúnem condições para, sozinhas, produzirem os efeitos que a Constituição quer). Noutro giro verbal, não cabe mandado de injunção contra comissões de órgãos administrativos. Só contra omissão do Poder Legislativo. E omissões que impedem o cabal cumprimento de normas constitucionais de eficácia limitada". (CARRAZZA, 1993). "Assim, em conformidade com a classificação apresentada por José Afonso da Silva, só as normas de eficácia limitada podem servir de parâmetro para a ação direta de inconstitucionalidade por omissão. [...] Para uma delimitação conceitual da omissão inconstitucional, é preciso que se deixe claro, desde logo, que só haverá essa omissão no domínio das chamadas normas constitucionais de eficácia limitada, pois são as únicas que dependem ora de providências normativas do Poder Legislativo, ora de prestações positivas do Poder Executivo. Vale dizer, a omissão inconstitucional está relacionada com as normas constitucionais de eficácia limitada. Isso significa que, por óbvio, se todas as normas detivessem eficácia plena, não haveria lugar para a omissão inconstitucional". (CUNHA JÚNIOR, 2004). "Não há que se falar em omissão legislativa inconstitucional diante de normas constitucionais autoaplicáveis [...], de forma que toda norma constitucional diretamente aplicável exclui uma omissão juridicamente relevante". (CAMPOS, 2011, p. 51). "O mandado de injunção é destinado às normas constitucionais de eficácia limitada ou reduzida, não possuidoras de normatividade suficiente para, de imediato, gerarem seus efeitos, necessitando de legislação infraconstitucional". (FARIA, 2001). "Somente as normas constitucionais de eficácia limitada podem ser objetos da ação de inconstitucionalidade por omissão, pois somente estas dependem de normas infraconstitucionais para sua efetividade". (FOLADOR, 2015). "O parâmetro do controle abstrato [por omissão] consiste em norma constitucional de eficácia limitada, declaratória de princípio institutivo ou princípio programático, que tenha imposto o dever de legislar violado". (PEÑA DE MORAES, 2012, p. 260). "Se o seu caráter é o de suprir omissão legislativa, descabe o mandado se a norma, justamente por conter aplicabilidade imediata, desnecessitar de regulamentação". (SLAIBI FILHO, 2006, p. 435). "A Ação Direta de Inconstitucionalidade por Omissão é o instituto jurídico criado pelo Poder Constituinte Originário para sanar, em sede de controle de constitucionalidade abstrato e com eficácia erga omnes, a ausência de norma infraconstitucional suplementar de dispositivo constitucional de eficácia limitada ou restrita". (SILVA, 2012). "Não é a mera omissão legislativa que permite a injunção. É necessário que a ausência da norma torne inviável o exercício de direitos, liberdades e prerrogativas. Portanto, quando a Constituição contiver toda a normação necessária para a eficácia de sua disposição, seu desrespeito não será atacado por injunção, mas pelos remédios comuns, como o mandado de segurança, mesmo que inexista lei complementando as disposições constitucionais. A injunção não é um modo de tornar de fato respeitadas as normas de eficácia plena, mas sim de tornar plenamente eficazes as de eficácia limitada. Assim, é fundamental que a norma constitucional cuja regulamentação é omitida seja de eficácia limitada, é dizer, seja daquelas que 'não receberam, do constituinte, normatividade suficiente para sua aplicação, o qual deixou, para o legislador ordinário, a tarefa de completar a regulamentação da matéria nelas traçada em princípio ou esquema". (SUNDFELD, 2011). "Não se pode olvidar o telos do mandado de injunção, qual seja, o de viabilizar o exercício de um direito concedido por norma constitucional de eficácia limitada". (QUEIROZ, 1998). 
O próprio Supremo Tribunal Federal já se manifestou algumas vezes no sentido de que os instrumentos processuais previstos para a solução das omissões legislativas inconstitucionais não são adequados quando se está diante de normas de aplicação imediata e eficácia plena. Assim, por exemplo, no MI 144/SP, julgado em 1992, o STF firmou entendimento, seguido em vários pronunciamentos posteriores, inclusive de $2015^{2}$, de que o interesse processual capaz de justificar a impetração do mandado de injunção pressupõe uma norma de eficácia limitada. Por isso, não seria cabível o mandado de injunção se se estivesse diante de normas de eficácia plena e aplicabilidade imediata ou se se perante uma norma de eficácia limitada já regulamentada ${ }^{3}$.

Referida ideia parece fazer sentido. Afinal, se a norma constitucional pode desde já produzir os efeitos desejados, independentemente de uma regulamentação legal, não haveria mesmo necessidade de uma ação judicial para instigar a produção de uma lei regulamentadora.

Apesar disso, será demonstrado neste artigo que referida ideia está equivocada, pois se alicerça em uma concepção ultrapassada da eficácia das normas constitucionais. Conforme ficará mais bem esclarecido ao longo do texto, qualquer norma constitucional cujos efeitos estejam sendo frustrados por uma omissão do Estado é passível de ensejar uma inconstitucionalidade por omissão, independentemente de se tratar de norma de eficácia plena, contida ou limitada. Como consequência, será defendido um modelo de correção das omissões inconstitucionais que leve em conta o caráter expansivo, progressivo, aberto, contínuo e inacabado do

2 STF, MI 833, rel. Min. Carmen Lúcia (rel. para acórdão: Min. Roberto Barroso), j. 11/6/2015. No referido julgado, o voto da Min. Carmen Lúcia iniciou-se com a seguinte afirmação: "O mandado de injunção é ação constitucional de natureza mandamental, destinada a integrar a regra constitucional limitada, em sua eficácia, pela ausência de norma que assegure a ela o vigor pleno".

3"É impróprio o uso do mandado de injunção para o exercício de direito decorrente de norma autoaplicável" (STF, MI 97/MG, rel. Min. Sidney Sanches, j. 10/2/1990); "Não há interesse processual necessário à impetração de mandado de injunção, se o exercício do direito, da liberdade ou da prerrogativa constitucional da requerente não está inviabilizado pela falta de norma infraconstitucional, dada a recepção de direito ordinário anterior" (STF, MI 144, Relator(a): Min. Sepúlveda Pertence, Tribunal Pleno, julgado em 03/08/1992). "A jurisprudência desta Suprema Corte firmou-se no sentido de que o art. 37, X, da Magna Carta já foi objeto de regulamentação, no âmbito federal, pela Lei 10.331/2001, com as alterações promovidas pela Lei 10.697/2003. Dessa forma, à míngua de norma constitucional de eficácia limitada pendente de regulamentação, não há lastro para a concessão da pretendida ordem injuncional coletiva. Precedentes do Plenário: MI 5313 ED, Rel. Min. Cármen Lúcia, DJe de 13.6.2014; MI 5085 ED, Rel. Min. Ricardo Lewandowski, DJe de 06.6.2014; MI 4265 AgR, Rel. Min. Gilmar Mendes, DJe de 02.6.2014; e MI 4831 AgR, Rel. Min. Teori Zavascki, DJe de 28.08.2013" (STF, MI 2411 AgR, Relator(a): Min. ROSA WEBER, Tribunal Pleno, julgado em 01/08/2014, ACÓRDÃO ELETRÔNICO DJe-165 DIVULG 26-08-2014 PUBLIC 27-08-2014). 
A eficácia incompleta das normas constitucionais: desfazendo um mal-entendido sobre o parâmetro normativo das omissões constitucionais

de proteção da dignidade e reconheça a multiplicidade de deveres que emanam das normas de direitos fundamentais.

\section{EFICÁCIA DAS NORMAS E OMISSÃO INCONSTITUCIONAL}

Afirmar que o parâmetro do controle de constitucionalidade por omissão há de envolver necessariamente uma norma constitucional de eficácia limitada significa, em termos práticos, que não seria possível haver inconstitucionalidade por omissão se (1) a norma constitucional "desrespeitada" pelo silêncio legislativo fosse de eficácia plena ou contida ou se (2) a norma constitucional fosse de eficácia limitada, mas já tivesse ocorrido uma regulamentação capaz de permitir que a norma produza os seus efeitos. $\mathrm{Na}$ segunda hipótese, ainda restaria a possibilidade de haver a omissão inconstitucional se a regulamentação não fosse suficiente, o que poderia dar azo ao problema da omissão parcial ou da proibição de insuficiência, que não será, contudo, objeto de preocupação neste artigo. O que se analisa aqui é o equívoco da primeira hipótese, ou seja, será defendida a posição segundo a qual até mesmo algumas normas tradicionalmente classificadas como de eficácia plena ou contida poderão exigir a adoção de medidas regulamentadoras passíveis de ensejar a omissão inconstitucional.

A ideia de que apenas as normas de eficácia limitada podem servir como parâmetro para o controle de constitucionalidade por omissão pressupõe que algumas normas constitucionais são autossuficientes para produzirem plenamente todos os seus efeitos, podendo ser imediatamente aplicadas independentemente de qualquer regulamentação posterior, e outras, pelo contrário, dependem de uma atuação legislativa para alcançarem sua eficácia plena e serem aplicadas pelos órgãos estatais.

Como se sabe, tal proposta é uma decorrência direta da classificação triádica desenvolvida por José Afonso da Silva, amplamente adotada até hoje pela dogmática constitucional e pela jurisprudência do $\mathrm{STF}^{4}$. Referida classificação adota uma distinção, quanto à eficácia e aplicabilidade, de três tipos de normas constitucionais: (a) normas que, por si, já reúnem todos os elementos necessários para a produção de todos os efeitos desejados, podendo ser desde já aplicadas plenamente,

4 O livro de referência aqui adotado é: SILVA, 1998. 
independentemente de qualquer regulamentação futura (normas de eficácia plena $)^{5}$; (b) normas que, embora reúnam todos os elementos para a imediata produção de seus efeitos, são passíveis de restrição/regulamentação por lei infraconstitucional (normas de eficácia contida $)^{6}$ e (c) normas que dependem de uma regulamentação posterior que lhes complemente a eficácia (normas de eficácia limitada) ${ }^{7}$.

Assim, de acordo com essa classificação, apenas as normas que não podem ser imediatamente aplicadas, por dependerem de uma regulamentação posterior que lhes complemente a eficácia, poderiam causar uma situação de inconstitucionalidade por omissão, bastando para tanto que o órgão responsável pela regulamentação ficasse inerte, ou seja, não cumprisse o seu dever constitucional de aprovar a respectiva norma regulamentadora. A inércia regulamentar impediria que a norma produzisse efeitos, justificando a adoção de mecanismos judiciais de superação da omissão inconstitucional.

De um modo geral, as normas constitucionais de eficácia limitada adotam uma estrutura condicionada, remetendo à lei a tarefa de preencher o seu sentido normativo. Assim, por exemplo, quando o Texto Constitucional estabelece que "a lei disporá sobre..." ou "o direito X será exercido conforme dispuser a lei" ou "o Congresso Nacional deverá regulamentar, no prazo de X dias, o direito $\mathrm{Y}^{\prime \prime}$ etc., está-se diante de uma típica norma de eficácia limitada apta a produzir, pela visão canônica, a omissão inconstitucional.

Nas linhas seguintes, serão expressas algumas críticas, visando a justificar, senão o abandono total da classificação de José Afonso da Silva, pelo menos, uma reformulação crítica de sua proposta original. Se ficar evidente que referida classificação não é totalmente adequada para bem compreender o fenômeno da eficácia das normas constitucionais, será percebido o fato de ser um equívoco afirmar que apenas as normas de eficácia limitada podem produzir omissões inconstitucionais.

\footnotetext{
5 Nas palavras do próprio autor: "Aquelas que, desde a entrada em vigor da constituição, produzem, ou têm possibilidade de produzir, todos os efeitos essenciais, relativamente aos interesses, comportamentos e situações, que o legislador constituinte, direta e normativamente, quis regular". (SILVA, 1998, p. 101).

6"Aquelas em que o legislador constituinte regulou suficientemente os interesses relativos à determinada matéria, mas deixou margem à atuação restritiva por parte da competência discricionária do Poder Público, nos termos que a lei estabelecer ou nos termos de conceitos gerais nela enunciados" (SILVA, 1998, p. 116).

7"Através das quais o legislador constituinte traça esquemas gerais de estruturação e atribuições de órgãos, entidades ou institutos, para que o legislador ordinário os estruture em definitivo, mediante lei" (SILVA, 1998, p. 126).
} 
A eficácia incompleta das normas constitucionais: desfazendo um mal-entendido sobre o parâmetro normativo das omissões constitucionais

\section{A SUPERAÇÃO DA CLASSIFICAÇÃO DE JOSÉ AFONSO DA SILVA}

José Afonso da Silva escreveu a sua famosa proposta de taxinomia das normas constitucionais em 1966, numa época em que o constitucionalismo padecia de grave crise de efetividade, já que se vivia em um regime de exceção. Nessa conturbada realidade, José Afonso da Silva conseguiu uma proeza: obteve reconhecimento por uma teoria que tratava justamente da eficácia das normas constitucionais ${ }^{8}$. Sua teoria atingiu tal nível de aceitação no centro jurídico brasileiro que, ainda hoje, passados 40 anos, é adotada pelo Supremo Tribunal Federal em alguns casos ${ }^{9}$.

Várias foram as tentativas de refutação da teoria desde a sua formulação original, mas poucas alcançaram o nível de precisão daquelas lançadas por Virgílio Afonso da Silva no texto "Eficácia das Normas Constitucionais" (SILVA, 2010). Com base nelas, podem ser apontados pelo menos três aspectos que justificam a superação da classificação de JAS. Esses três aspectos podem ser sintetizados da seguinte forma:

(1) a proposta de José Afonso da Silva desvaloriza as normas de eficácia limitada, dificultando que delas se extraia a sua máxima eficácia;

(2) a proposta de José Afonso da Silva trata as normas de eficácia plena como normas irrestringíveis, o que não é condizente com a compreensão do caráter necessariamente relativo dos direitos;

(3) a proposta de José Afonso da Silva trata algumas normas (em particular, as de eficácia plena e as de eficácia contida) como "bastantes em si", reconhecendo-lhes uma autossuficiência que pode prejudicar o seu desenvolvimento normativo e consequentemente sua eficácia.

Vejamos, de per si, cada uma dessas críticas, verificando como elas interferem no problema das omissões inconstitucionais.

Em primeiro lugar, a ideia de norma de eficácia limitada pode levar a um esvaziamento normativo da constituição, na medida em que se cria um pretexto para

\footnotetext{
8 Como explica Virgílio Afonso da Silva, "embora o título do livro de José Afonso da Silva seja Aplicabilidade das Normas Constitucionais, o conceito mais importante de seu trabalho é a eficácia das normas constitucionais" (Op. cit., p. 210).

9 Tal incorporação da teoria à prática jurisprudencial, contudo, não é totalmente coerente. Além de haver, com certa frequência, equívocos de nomenclatura (confundindo, por exemplo, as normas de eficácia contida com as normas de eficácia limitada), o conceito "normas de eficácia limitada" quase sempre é mobilizado para esvaziar o significado normativo da norma, como se as referidas normas fossem desprovidas de qualquer eficácia, o que não corresponde ao que José Afonso da Silva defendia.
} 
negar aplicação a uma norma constitucional até que o legislador resolva regulamentála. Não é à toa que o conceito, em geral, é mobilizado, ainda que de forma distorcida de sua formulação original, para negar eficácia à norma constitucional, como se as normas de eficácia limitada fossem normas sem eficácia alguma ${ }^{10}$.

O curioso é que José Afonso da Silva, ao desenvolver o conceito de norma de eficácia limitada, pretendia oferecer uma tipologia capaz de superar a velha concepção de norma constitucional não-auto-aplicável. Para isso, defendeu que toda norma constitucional possuiria algum nível de eficácia imediata, funcionando, no mínimo, como parâmetro para a revogação das regras preexistentes que lhes sejam contrárias, para o controle de constitucionalidade e para a interpretação jurídica. Ou seja, mesmo as normas constitucionais com o menor grau de eficácia poderiam ter a força de revogar e anular a legislação contrária ao seu sentido normativo e poderiam auxiliar a compreensão de outras normas jurídicas como vetores interpretativos. É o que ele denominava de eficácia negativa das normas constitucionais ${ }^{11}$. Embora a ideia de que todas as normas constitucionais possuem uma "eficácia negativa" tenha sido um avanço na época em que foi desenvolvida, hoje se pode dizer que a eficácia das normas de eficácia limitada não se esgota nisso. Afinal, foram desenvolvidos mecanismos de superação das omissões inconstitucionais para além da chamada "eficácia negativa" para se permitir, em muitas ocasiões, a

10 Em geral, a jurisprudência do STF invoca o conceito de norma de eficácia limitada como sinônimo de norma não-auto-aplicável. Confiram-se alguns exemplos: "O Supremo Tribunal Federal fixou entendimento no sentido de que o artigo 37, I, da Constituição do Brasil [redação após a EC 19/98], consubstancia, relativamente ao acesso aos cargos públicos por estrangeiros, preceito constitucional dotado de eficácia limitada, dependendo de regulamentação para produzir efeitos, sendo assim, não auto-aplicável. Precedentes. Agravo regimental a que se dá provimento" (STF, RE 544655 AgR, Relator(a): Min. EROS GRAU, j. 09/09/2008). "A regra inscrita no art. 192, § 3º da Carta Política norma constitucional de eficácia limitada - constitui preceito de integração que reclama, em caráter necessário, para efeito de sua plena incidência, a mediação legislativa concretizadora do comando nela positivado. O Congresso Nacional desempenha, nesse contexto, a relevantíssima função de sujeito concretizante da vontade formalmente proclamada no texto da Constituição. Sem que ocorra a interpositio legislatoris, a norma constitucional de eficácia limitada não produzirá, em plenitude, as consequências jurídicas que the são pertinentes. Ausente o ato legislativo reclamado pela Constituição, torna-se inviável pretender, desde logo, a observância do limite estabelecido no art. 192, § $3^{\circ}$, da Carta Federal" (STF, RE 168501, Relator(a): Min. CELSO DE MELLO, j. 28/09/1993).

11 Para José Afonso da Silva, a "eficácia negativa", inerente a toda norma constitucional, implica o reconhecimento de uma eficácia jurídica imediata, direta e vinculante na medida em que: I - estabelece um dever para o legislador ordinário; II - condiciona a legislação futura, com a consequência de serem inconstitucionais as leis ou atos que as ferirem; III - informa a concepção do Estado e da sociedade e inspira a sua ordenação jurídica, mediante a atribuição de fins sociais, proteção dos valores da justiça social e revelação dos componentes do bem comum; IV - constitui sentido teleológico para a interpretação, integração e aplicação das normas jurídicas; V - condicionam a atividade discricionária da Administração e do Judiciário; VI - cria situações subjetivas, de vantagem ou desvantagem. 
A eficácia incompleta das normas constitucionais: desfazendo um mal-entendido sobre o parâmetro normativo das omissões constitucionais

correção judicial da ausência de norma regulamentadora, inclusive ao ponto de se admitir a construção de soluções normativas pelo próprio Poder Judiciário.

Além disso, algumas obrigações jurídicas podem ser, em determinadas circunstâncias, diretamente extraídas dos princípios que emanam das normas de eficácia limitada, com uma força normativa que vai muito além da mera eficácia negativa. De qualquer modo, nesse ponto, a mobilização do conceito de eficácia limitada não gera tanto problema para a compreensão do fenômeno da omissão inconstitucional, pois, mesmo que se reconheça algum nível de eficácia a essas normas, o que se está a defender é que, para a produção de alguns efeitos importantes, a eficácia da norma depende de uma regulamentação normativa. E é justamente a ausência dessa regulamentação normativa que cria um obstáculo para a realização plena do direito, caracterizando a omissão inconstitucional ${ }^{12}$.

O segundo ponto problemático na proposta de José Afonso da Silva envolve a distinção entre norma de eficácia plena e norma de eficácia contida. A rigor, não haveria diferença substancial entre essas duas espécies normativas, já que ambas teriam, no primeiro momento, eficácia plena e aplicabilidade imediata. A diferença ocorreria não no âmbito da aplicação ou da eficácia, mas da possibilidade de restrição, pois se pressupõe que existem algumas normas constitucionais irrestringíveis (de eficácia plena) e algumas delas passíveis de restrição (de eficácia contida ${ }^{13}$ ). Então, as normas de eficácia plena e contida possuiriam o mesmo nível de aplicação e eficácia, não havendo sentido distingui-las quanto a esses aspectos que são aqueles centrais do modelo triádico. Em verdade, normas de eficácia plena e normas de eficácia contida são duas espécies de norma de eficácia plena e aplicabilidade imediata: as primeiras são normas de eficácia plena e aplicabilidade imediata não passíveis de restrição, ao passo que as outras são normas de eficácia plena e aplicabilidade imediata passíveis de restrição.

12 Assim, por exemplo, o Texto Constitucional que dispõe que "a lei punirá qualquer discriminação atentatória dos direitos e liberdades fundamentais" (artigo $5^{\circ}$, inc. XLI) contém um nível de eficácia desde já verificável, mas a produção plena de seus efeitos dependerá de uma ação legislativa que estabeleça as condições para a punição constitucionalmente pretendida, dando ensejo à configuração da omissão inconstitucional.

13 Virgílio Afonso da Silva critica a denominação "norma de eficácia contida", por entender que não faz sentido denominar como contida a norma cuja eficácia possa ser restringida, já que o termo expressa algo já realizado, e não apenas potencial. Por essa razão, é preferível usar o termo "contível" ou "restringível". (Op. cit., p. 220-221). 
Além disso, mesmo naquilo em que supostamente as diferencia (possibilidade de restrição), é bastante difícil sustentar a dicotomia de um modo relevante, pois a ideia de norma irrestringível depende de alguns pressupostos muito difíceis de sustentar ${ }^{14}$. Basta dizer que, no campo dos direitos fundamentais, em que a carga de importância axiológica da norma constitucional é bastante elevada, são raros os autores que defendem a existência de direitos ilimitados e absolutos ${ }^{15}$. Nesse âmbito, até mesmo as normas de eficácia plena seriam passíveis de restrições, o que justificaria a superação da dicotomia. Também nesse ponto, entretanto, o abandono da classificação de José Afonso da Silva não ocasiona maiores dificuldades de compreensão das omissões inconstitucionais, pois, em geral, quando se fala em inconstitucionalidade por omissão, o foco da análise se volta precipuamente para o âmbito de proteção dos direitos fundamentais e não para o nível de intervenção ou restrição, algo que, em tese, diminuiria o âmbito de proteção; ou seja, em princípio, a ausência de uma normatização sobre as restrições ao direito fundamental não ocasionaria uma inconstitucionalidade por omissão, pois não seria um obstáculo capaz de inviabilizar o imediato exercício do referido direito ${ }^{16}$.

14 Há alguns artigos constitucionais que poderiam se encaixar de um modo muito preciso no conceito de norma de eficácia plena na forma pretendida por José Afonso da Silva, ou seja, normas que produzem todos os seus efeitos, independentemente de regulação, e que não são passíveis de restrição normativa, mas dificilmente tais artigos podem ser considerados como normas propriamente ditas. Assim, por exemplo, o $\S 1^{\circ}$, do art. 18, da $\mathrm{CF} / 88$, ao estabelecer que "Brasília é a capital federal" ou o artigo que estabelece que "a língua portuguesa é a língua oficial da República Federativa do Brasil" (art. 13) são típicos exemplos de norma constitucional de eficácia plena e não são passíveis de restrições. Há dois fatores, porém, que justificam a manutenção do que foi expresso acima, ou seja, mesmo as normas de eficácia plena seriam restringíveis. Primeiro, porque dificilmente esses artigos podem ser encaixados em um conceito estrito de norma jurídica. Em rigor, são fatos institucionalizados constitucionalmente e não regras de conduta ou diretrizes de ação. Sua linguagem não é prescritiva, mas impositiva, situada no plano do ser e não do dever-ser. Em segundo lugar, o conceito adotado por José Afonso da Silva abrange até mesmo alguns direitos fundamentais (liberdade de expressão, por exemplo) e é justamente esse tipo de inclusão que enseja o problema assinalado no texto, vale dizer: dificilmente seria possível cogitar na existência de um direito fundamental ilimitado. A única forma de se pensar em direitos fundamentais absolutos seria com a adoção da teoria dos limites imanentes, discussão esta que foge aos escopos deste estudo. Sobre isso: Silva, 2006, p. 23-51.

15 A afirmação de que não existem direitos absolutos já se tornou um lugar-comum no discurso constitucional, mas precisa ser analisada com cautela. Embora essa afirmação possa ser correta, a forma banalizada e distorcida com que se reproduz esse pensamento está dando margem ao surgimento de um discurso pouco comprometido com os direitos fundamentais, ameaçando concretamente a ideia de dignidade humana. Por isso, é preciso deixar claro que a limitação de um direito fundamental somente se justifica em circunstâncias especiais, atendidos diversos requisitos formais e materiais, sem os quais a relativização se torna juridicamente inválida.

16 Conforme se verá mais à frente, essa ideia deve ser vista com temperamentos, pois, em algumas circunstâncias, a regulação da restrição pode ser útil para aumentar a eficácia do direito fundamental. Além disso, existem algumas normas constitucionais que impõem deveres de legislar em matéria de restrição de direitos. É o caso, por exemplo, do dever constitucional dirigido ao legislador de restringir a propaganda comercial de "tabaco, bebidas alcoólicas, agrotóxicos, medicamentos e terapias" (artigo $220, \S 4^{\circ}$, da CF/88) ou então de criminalizar o racismo (artigo $5^{\circ}$, inc. XLII), entre vários outros. 
A eficácia incompleta das normas constitucionais: desfazendo um mal-entendido sobre o parâmetro normativo das omissões constitucionais

Há o terceiro ponto, contudo, intimamente relacionado ao que se discutiu no parágrafo antecedente, que justifica uma reavaliação da tese de que apenas as chamadas normas de eficácia limitada são passíveis de possibilitar a omissão inconstitucional. É que o conceito de normas de eficácia plena se baseia numa falsa crença de autossuficiência de determinadas normas constitucionais que, além de equivocada, é perigosa. De acordo com essa crença, o dever do Estado, em matéria de legislação, estaria plenamente cumprido com a mera positivação constitucional da norma; ou seja, se a norma é de eficácia plena e de aplicação imediata, não há mais nada a ser feito no nível legislativo, já que a norma é "bastante em si"17, sendo inadequado falar-se em omissão inconstitucional pela ausência da regulação da referida norma. É justamente esse ponto que merece ser explorado para justificar uma reavaliação da afirmação de que apenas as normas de eficácia limitada são passíveis de ensejar a omissão inconstitucional. Conforme será demonstrado, até mesmo as normas de eficácia plena e aplicabilidade imediata podem exigir a adoção de alguma medida legislativa capaz de lhe dar ainda mais eficácia ${ }^{18}$.

\section{NORMAS DE EFICÁCIA PLENA (OU CONTIDA) E OMISSÃo INCONSTITUCIONAL}

O conceito de norma de eficácia plena, da forma como é exposta tradicionalmente, negligencia a multiplicidade de deveres decorrentes das normas constitucionais. Tomando como parâmetro as normas constitucionais que definem direitos fundamentais, percebe-se facilmente que tais normas impõem ao Estado um complexo variado de tarefas, que vão muito além do mero agir em conformidade com a norma constitucional. Além do dever de respeito (não violar a norma ou cumprir o que ela determina), também existem deveres de proteção, promoção, organização etc., que, em geral, exigem complementação normativa para alcançarem os resultados

17 A expressão é de Pontes de Miranda, conforme citado por Virgílio Afonso da Silva (Op. cit., p. 229). 18 Como assinala Virgílio Afonso da Silva: (1) toda norma que garante direitos fundamentais pode ser restringida; (2) toda norma que garante direitos fundamentais pode (às vezes, deve) ser regulamentada (Op. cit., p. 230). E, citando Konrad Hesse, assinala: "Para produzir efeitos, a maioria dos direitos fundamentais depende de uma regulamentação jurídica das relações e dos âmbitos da vida que eles devem garantir. Essa regulamentação é, em primeira linha, tarefa do legislador ordinário. Ela pode se basear em uma exigência constitucional expressa [...]. Mas ela pode também se mostrar necessária independentemente desse tipo e exigência" (Op. cit., p. 246). 
desejados $^{19}$. Esses deveres que emanam das normas de direitos fundamentais (e de direitos humanos) não dependem da forma textual em que a norma é expressa. A existência ou não de reserva legal ou de uma ordem explícita dirigida aos agentes estatais não é o mais relevante para extrair todas as ações a serem adotadas para a máxima efetivação da norma ${ }^{20}$. O que importa é o fundamento de valor que emana da norma, e o tipo de comportamento que pode ser exigido com suporte naquele.

O pleno cumprimento da igualdade, por exemplo, não se restringe a um respeito estatal ao mandamento de não discriminação (dever de respeito). É fundamental, do mesmo modo, que o Estado desenvolva mecanismos para evitar que as pessoas pratiquem a discriminação, devendo ser criada uma estrutura jurídico-institucional de combate ao preconceito (dever de proteção) e adotadas medidas para reduzir as desigualdades socioeconômicas da sociedade, inclusive mediante a previsão de mecanismos de ação afirmativa (dever de promoção da igualdade). Assim, para que o ideal de igualdade seja plenamente alcançado, são necessárias, sem dúvida, intervenções legislativas e administrativas que proporcionem maior densificação do mandamento constitucional e, para isso, é preciso aprovar normas de combate ao racismo ou de favorecimento de grupos vulneráveis (ações afirmativas), entre outras medidas semelhantes ${ }^{21}$.

Outro exemplo pode ser desenvolvido focando no direito à integridade moral e física. A norma veda, independentemente de regulamentação, uma série de atos estatais que seriam violadores da integridade, como, por exemplo, a prática de tortura

19 Sobre isso: MARMELSTEIN, 2008, p. 284-289, onde se explica que todo direito fundamental gera, para o estado, um dever de respeito, proteção e promoção, ou seja, o Estado tem o dever de respeitar (não violar o direito), proteger (não deixar que o direito seja violado) e promover (possibilitar que todos usufruam) esses direitos. Assim, o dever de respeito, proteção e promoção, inerente a qualquer direito fundamental, impõe uma multiplicidade de tarefas ao poder público, de modo que a concretização plena dessas normas não se esgota em um mero agir ou não agir do Estado.

20 Sobre isso, tentando desfazer um mal-entendido sobre o papel das reservas legais dos direitos fundamentais no sistema jurídico brasileiro: Silva, 2009, p. 605-618. No referido artigo, Virgílio Afonso da Silva demonstra que, no Brasil, não há diferença substancial, quanto à possibilidade de restringibilidade ou quanto à liberdade de conformação do legislador, entre direitos fundamentais submetidos a reserva legal e direitos fundamentais não submetidos a reserva legal. Não há, assim, um sistema de reserva legal na Constituição brasileira que justifique algum tipo de diferenciação forte entre os direitos submetidos a reserva legal e os direitos não submetidos a reserva legal.

21 A esse respeito, tramita, no STF, o MI 4.733/DF, em que se pretende reconhecer a omissão legislativa em decorrência da não criminalização da homofobia. Embora o debate envolva questões mais complexas sobre, por exemplo, a existência ou não de um dever constitucional de criminalizar a homofobia ou, o que é ainda mais complicado, a possibilidade ou não de uma colmatação judicial da mora legislativa (de modo a permitir a criação judicial de tipos penais com as respectivas sanções), parece óbvio que o principal parâmetro normativo capaz de justificar a impetração do mandado de injunção é a igualdade (não discriminação), especificamente o dever de proteção da igualdade, que, mesmo direitos fundamentais, "de aplicação direta e imediata", são capazes de ensejar omissões inconstitucionais. 
A eficácia incompleta das normas constitucionais: desfazendo um mal-entendido sobre o parâmetro normativo das omissões constitucionais

a um interrogando ou de maus-tratos a presos. Para isso, obviamente, não há qualquer necessidade de uma ação judicial visando a suprir uma suposta omissão legislativa ou algo do gênero. Há, entretanto, alguns efeitos da norma que dependem sim de regulamentação. Basta ver que a imputação da responsabilidade internacional do Brasil no caso Maria da Penha (com posterior aprovação da lei respectiva - Lei 11.340/2006) foi justamente pela ausência de um sistema eficiente de proteção das mulheres contra violência doméstica.

No caso, a Comissão Interamericana de Direitos Humanos constatou que o problema não se restringia àquela vítima em particular e, portanto, a solução estrutural do problema demandaria a adoção de uma política pública mais integral de combate à violência doméstica, visando a conceder plena eficácia ao dever de proteção que emana da norma garantidora da integridade. Nas palavras da Comissão, a "violação segue um padrão discriminatório com respeito a tolerância da violência doméstica contra mulheres no Brasil por ineficácia da ação judicial", razão pela qual o Brasil deveria, além de apurar as responsabilidades daí decorrentes, reparar pronta e efetivamente a vítima da violência, bem como adotar "medidas, no âmbito nacional, para eliminar essa tolerância do Estado ante a violência doméstica contra mulheres"22.

A mesma lógica pode ser adotada em relação à liberdade de expressão. Uma norma que, na classificação de José Afonso da Silva, seria tipicamente de eficácia plena e, em tese, não estaria submetida a nenhum tipo de reserva legal explícita que justificasse, formalmente, a sua restrição. Sem dúvida, alguns efeitos produzidos pela referida norma constitucional independem de regulamentação, sobretudo aqueles relacionados ao dever de respeito (não censurar, por exemplo). Algumas intervenções legislativas, entretanto, poderiam ser necessárias ou, pelo menos, úteis para que alguns efeitos fossem alcançados plenamente, sobretudo se o que se intenta é um ambiente de circulação de ideias livre, plural e democrático (aqui o exemplo é de Virgílio Afonso da Silva). Considere-se, por exemplo, a necessidade de regulação da

22 CIDH, Relatório 54/01, Caso 120.51 Maria da Penha Maia Fernandes v. Brasil, j. 4 de abril de 2001. Em um caso posterior, decidido não no âmbito da Comissão, mas da Corte Interamericana de Direitos Humanos (Corte IDH, Caso González y otras (Campo Algodonero) vs. México. j. 16 de noviembre de 2009), foi desenvolvido com precisão o sentido do dever estatal de proteção em relação à violência contra as mulheres, sobretudo em razão de padrões estruturais de violações de direitos. Para a Corte, "los Estados deben adoptar medidas integrales para cumplir con debida diligencia en casos de violencia contra las mujeres. En particular, deben contar con un adecuado marco jurídico de protección, con una aplicación efectiva del mismo, con políticas de prevención y prácticas que permitan actuar de una manera eficaz ante las denuncias". 
Internet, visando, entre outras coisas, a garantir a neutralidade estatal no controle das informações transmitidas, ou então proporcionar, por meio de políticas públicas, o pleno acesso a grupos desfavorecidos aos meios tecnológicos (inclusão digital).

Se incluirmos o financiamento da cultura ou o direito à informação e à educação como pressupostos para o exercício da liberdade de expressão, também teríamos um vasto campo onde seria importante haver normas regulamentadoras capazes de proporcionar a promoção de um amplo e plural "mercado de ideias"; isto é, é equívoco pensar que a proteção normativa da liberdade de expressão está plenamente garantida com a mera positivação constitucional e com o cumprimento do chamado dever de respeito com teor negativo (de abstenção ou de defesa).

Além da não intervenção do Estado na livre circulação de ideias, o Ente estatal deve adotar diversas medidas para garantir a manifestação de pensamento de grupos "sem voz política" ou então para reduzir a concentração de poder dos meios de comunicação coletiva ou para evitar que os particulares impeçam outros particulares de se manifestarem ou para punir o abuso do exercício etc.

Além disso, não se pode descartar a possibilidade de ocorrer uma omissão inconstitucional pela ausência de uma regulamentação das restrições a direitos fundamentais ${ }^{23}$. Esse ponto precisa ser bem entendido, pois parece ser contraditório em relação à própria ideia de omissão inconstitucional. Afinal, uma restrição, como é óbvio, limita o âmbito de proteção e, consequentemente, a eficácia do direito fundamental restringido. Logo, como o instituto da omissão inconstitucional surge justamente em face da ineficácia do direito pela ausência de uma regulação, o direito, em princípio, estaria mais bem protegido se não existissem restrições. O problema aqui envolve dois aspectos sobre as restrições que justificam uma abordagem que não elimine, de antemão, a possibilidade de ocorrência de omissão inconstitucional pela não regulamentação das restrições.

23 Registre-se o fato de que, no paradigmático caso da greve dos servidores públicos (mandados de injunção 670/ES, 708/DF e 712/PA), onde houve a guinada jurisprudencial sobre a função do mandado de injunção, foi ressaltada no julgamento a importância de se regulamentar aquele direito não apenas como forma de garantir aos servidores uma ferramenta de reivindicação prevista constitucionalmente, mas também para evitar abusos no exercício do direito de greve, sobretudo envolvendo atividades públicas essenciais; isto é, a intervenção judicial de correção da mora legislativa foi justificada tanto para possibilitar o exercício do direito constitucional "de eficácia limitada" quanto para delimitar com precisão o seu âmbito de proteção e suas zonas de restrição. De certo modo, ante o caos jurídico provocado pela falta de uma lei regulamentadora do direito de greve, a solução dada pelo Supremo Tribunal Federal, supostamente favorável aos servidores, foi, em certo sentido, até mesmo prejudicial, pois criou condições muito mais restritas para o exercício daquele direito. 
A eficácia incompleta das normas constitucionais: desfazendo um mal-entendido sobre o parâmetro normativo das omissões constitucionais

O primeiro é que a restrição a um determinado direito fundamental também pode ser, em muitas ocasiões, instrumento de proteção e promoção de outros direitos fundamentais, que podem ser ameaçados com o exercício ilimitado do direito restringido. Assim, é possível que um determinado direito fundamental seja aniquilado pela ausência de restrições normativas de outro direito fundamental. Por exemplo, a ausência de uma delimitação minimamente precisa do âmbito de proteção da liberdade de expressão pode deixar os direitos de personalidade sem proteção. Do mesmo modo, sem a imposição de limites ao discurso de ódio, a liberdade de expressão pode funcionar como um instrumento de violação da igualdade (combate à discriminação), que também é um valor constitucionalmente relevante ${ }^{24}$. Na mesma linha, a ausência de restrições à propaganda de produtos nocivos pode submeter a risco a saúde dos consumidores e a proteção ao meio ambiente ${ }^{25}$.

O segundo ponto é que a ausência de restrições bem definidas pode ensejar um risco para a eficácia do próprio direito fundamental a ser restringido. É fácil entender se se tiver a ideia de que as restrições aos direitos fundamentais podem ser estabelecidas, com base na proporcionalidade, também por meio de decisões judiciais. Assim, sem parâmetros bem definidos a balizar o juízo de ponderação, há sempre o perigo de arbítrio/abuso judicial na restrição de direitos fundamentais, que pode se tornar sistemática se houver a estabilização da jurisprudência permitindo a restrição arbitrária. Nessas situações, a regulamentação das restrições pode ser útil para impedir o abuso judicial, podendo contribuir para o aumento da eficácia do direito em jogo ${ }^{26}$.

24 A esse respeito, o artigo 13, item 5, do Pacto de San Jose da Costa Rica, contém um dever de legislar especificamente sobre o hate speech, adotando uma estrutura normativa típica das normas de eficácia limitada: "a lei deve proibir toda propaganda a favor da guerra, bem como toda apologia ao ódio nacional, racial ou religioso que constitua incitamento à discriminação, à hostilidade, ao crime ou à violência".

25 Há, nesse caso, um verdadeiro dever constitucional de legislar, na medida em que há uma previsão constitucional prevendo a competência federal para legislar sobre "propaganda de produtos, práticas e serviços que possam ser nocivos à saúde e ao meio ambiente" (Artigo 220, §3º, da CF/88), e um dispositivo estabelecendo que "a propaganda comercial de tabaco, bebidas alcoólicas, agrotóxicos, medicamentos e terapias estará sujeita a restrições legais, nos termos do inciso II do parágrafo anterior, e conterá, sempre que necessário, advertência sobre os malefícios decorrentes de seu uso" (Artigo 220, $\S 4^{\circ}$, da $\left.\mathrm{CF} / 88\right)$.

26 Obviamente, em tais situações, quando a jurisprudência tiver se estabilizado no sentido de enfraquecer o âmbito de proteção de um determinado direito fundamental, admitindo restrições arbitrárias ao seu conteúdo, dificilmente o uso de instrumentos processuais típicos do controle das omissões constitucionais será útil, a não ser que se imagine um controle de convencionalidade das omissões no nível internacional. 
Assim, por exemplo, a ausência de uma delimitação precisa do âmbito de proteção da liberdade de expressão pode acarretar limitações arbitrárias ao referido direito fundamental, na medida em que os juízes poderão se sentir livres para relativizá-lo por motivos banais ${ }^{27}$. Do mesmo modo, a falta de uma definição exata do âmbito de proteção e das zonas de restrição da liberdade político-partidária pode ensejar uma proibição abusiva do exercício do direito, ao ponto, por exemplo, de se cassar arbitrariamente o direito de funcionamento de um partido político, tal como já ocorreu em relação ao Partido Comunista.

Outro exemplo ilustrativo pode ser desenvolvido com amparo na norma constitucional, a qual que prevê a liberdade profissional, que, na classificação de José Afonso da Silva, seria uma típica norma de eficácia contida ("Artigo $5^{\circ}$, inc. XIII - é livre o exercício de qualquer trabalho, ofício ou profissão, atendidas as qualificações profissionais que a lei estabelecer"). A leitura canônica da referida norma induz a se acreditar que a ausência de uma legislação definindo as "qualificações profissionais" necessárias ao exercício de uma determinada profissão nunca poderia ser considerada como um empecilho à liberdade. Afinal, em se tratando de uma norma de eficácia contida, a norma produziria imediatamente todos os seus efeitos, enquanto não fosse aprovada a legislação regulamentadora, equiparando-se a uma norma de eficácia plena. Assim, não seria necessária uma ação judicial para obrigar o legislador a regulamentar determinada profissão ou para suprir judicialmente a falta de norma regulamentar, uma vez que, na ausência de lei, o exercício daquela profissão não regulamentada seria livre e ilimitado.

27 Exemplo ilustrativo pode ser extraído do Caso "La Última Tentación de Cristo" vs. Chile, julgado pela Corte Interamericana de Direitos Humanos, em 2001. Os fatos que levaram à condenação do Chile foram motivados por uma ordem judicial, das cortes chilenas, determinando a censura ao filme "A Última Tentação de Cristo", com base na ideia de que blasfêmias não estariam inseridas no âmbito de proteção da liberdade de expressão e, portanto, poderiam ser previamente censuradas (obviamente, há várias nuances do caso, diante das peculiaridades do modelo institucional e normativo daquele País, que, embora relevantes, não interferem na ideia central contida nesta nota). Nesse caso, embora a violação da liberdade de expressão tenha sido praticada por um ato comissivo do Poder Judiciário, com base em normas que autorizavam a censura prévia, a Corte reconheceu que, além da medida usual de anulação do ato violador ao direito (típica dos casos de correção de inconstitucionalidades e inconvencionalidades por ação), haveria também a necessidade de mudanças no sistema normativo chileno, a fim de eliminar a possibilidade de se estabelecerem restrições arbitrárias em situações semelhantes (algo que é mais comum de ocorrer quando a violação do direito decorre de uma omissão). De certo modo, a decisão corrobora o que foi dito: às vezes, a regulação das restrições dos direitos fundamentais pode ampliar o âmbito de proteção do direito, evitando interpretações desproporcionais. Em outras palavras: mesmo que as normas que autorizem a censura prévia em violação à liberdade de expressão fossem anuladas, a violação poderia continuar sendo praticada se a interpretação restritiva quanto ao âmbito de proteção do direito fundamental não fosse mudada. E uma das soluções para isso seria por via da regulação das restrições na via legislativa. 
A eficácia incompleta das normas constitucionais: desfazendo um mal-entendido sobre o parâmetro normativo das omissões constitucionais

Apesar disso, basta ver o tratamento conferido à prostituição para verificar que a situação não é tão simples quanto se imagina. A ausência de uma norma regulamentando a prostituição enseja restrições arbitrárias de direitos (sobretudo previdenciários e trabalhistas) e, no extremo, serve de pretexto para a prática de violência moral e física contra as prostitutas, inclusive por agentes estatais.

Nota-se, neste caso, é que uma regulamentação desse ofício poderia elevar a dignidade do grupo estigmatizado, reforçando direitos que, em tese, já são garantidos, mas, na prática, são desrespeitados, e possibilitando, de modo muito mais pleno e efetivo, o exercício daquela liberdade profissional. Assim, não se deveria descartar de plano a adequação e necessidade de uma ação judicial visando a corrigir essa lacuna normativa, sobretudo ante a notória má vontade parlamentar de reconhecer os direitos decorrentes da prática da prostituição e imperiosa necessidade de se criar uma rede de proteção jurídica para esse grupo marginalizado.

Pode-se, com efeito, concluir, que, em determinadas situações, quando a ausência de uma norma regulamentadora está a dificultar a plena efetivação de um direito, é razoável tratar o problema como um caso de omissão inconstitucional. Isso permitirá que se desenvolvam soluções que ultrapassam os inúteis "apelos" ao legislador e reforçará a ideia de que a efetivação dos direitos é algo sempre inacabado, a exigir um contínuo esforço de densificação e concretização por parte de todos os agentes estatais.

\section{CONCLUSÃO}

Ao longo deste estudo, tentou-se demonstrar que o parâmetro normativo do controle das omissões inconstitucionais pode envolver até mesmo normas constitucionais que, na aparência, estão plenamente aptas a produzirem todos os seus efeitos. Ao contrário do que é reproduzido pela dogmática constitucional, não são apenas as normas de eficácia limitada que podem dar azo às omissões inconstitucionais. Sempre que a pretensão normativa da Constituição é frustrada por uma inação estatal tem-se um caso de omissão inconstitucional. Logo, o parâmetro normativo para verificar se há ou não uma inconstitucionalidade por omissão está nas 
normas constitucionais que impõem deveres de ação, inclusive as assim denominadas normas de eficácia plena ou contida.

De modo mais específico, pode-se afirmar o seguinte: todas as normas constitucionais produzem alguns efeitos que independem de regulação normativa e, consequentemente, em relação a tais efeitos, não há sentido em falar em omissão inconstitucional. É possível, todavia, existirem alguns efeitos que somente podem ser produzidos ou seriam mais bem produzidos se houvesse uma regulamentação normativa. Em situações assim, é possível falar em omissão inconstitucional mesmo em se tratando de normas que, tradicionalmente, são classificadas como normas de eficácia plena e aplicabilidade imediata.

Esse debate, embora primariamente situado no plano da dogmática constitucional, envolve uma preocupação axiológica consistente em reconhecer o caráter sempre incompleto da proteção dos direitos fundamentais, visando a estabelecer um modelo de jurisdição constitucional que tenha plena consciência da dimensão expansiva da dignidade e da justiça.

Ter consciência da dimensão expansiva da dignidade e da justiça significa perceber que a efetivação dos direitos é um contínuo que acompanha a acumulação do conhecimento, a aprendizagem sempre enriquecida pela experiência e a mudança de consciência que o amadurecimento intelectual produz. Também conduz a que nunca se esteja conformado com o estado de coisas, nem acreditar que já se atingiu o estádio final da evolução cultural. É preciso estar sempre aberto para o porvir e para o devir.

Considerar que a declaração em tom generalista e grandiloquente de um direito fundamental, por si, é bastante para garantir sua máxima efetividade é uma ingenuidade que não pode ser aceita. Pior ainda: acreditar que as gerações futuras não serão capazes de ampliar o nível de proteção institucional dos direitos fundamentais não é apenas um sinal de arrogância, mas, sobretudo, de ignorância quanto à própria história da humanidade. Ainda que se tenha a mais bela declaração de direitos já imaginada pelo ser humano (o que certamente não é o caso), nunca se poderá assinalar que se atingiu algo como a justiça absolutamente perfeita. Por isso, é preciso se abrir para o futuro e reconhecer o caráter sempre incompleto, contínuo e expansivo da dignidade e da justiça, o que pressupõe, por óbvio, tratar as normas constitucionais como um ponto de partida de um projeto em elaboração, jamais como ponto final de uma obra acabada. 
A eficácia incompleta das normas constitucionais: desfazendo um mal-entendido sobre o parâmetro normativo das omissões constitucionais

\section{REFERÊNCIAS}

CAMPOS, Carlos Alexandre de Azevedo. Atualidades do Controle Judicial da Omissão Legislativa Inconstitucional. In: DPU, n. 42, nov./dez, 2011.

CARRAZZA, Roque Antonio. Ação direta de inconstitucionalidade por omissão e mandado de injunção. Revista de Direito Constitucional e Internacional, vol. 3/1993 | p. 120 - 135, abr./jun, 1993.

CUNHA JÚNIOR, Dirley. Controle judicial das omissões do poder público: em busca de uma dogmática constitucional transformadora à luz do direito fundamental à efetivação da Constituição. São Paulo: Saraiva, 2004.

FARIA, Luiz Alberto Gurgel de. Controle da constitucionalidade na omissão legislativa: instrumentos de proteção judicial e seus efeitos. Curitiba: Juruá, 2001.

FOLADOR, Patrícia Micheli. Evolução histórica do controle de constitucionalidade no Brasil e a ação de inconstitucionalidade por omissão. Doutrinas Essenciais de Direito Constitucional, vol. 10/2015, p. 1121 - 1151, Ago. 2015.

MARMELSTEIN, George. Curso de Direitos Fundamentais. São Paulo: Atlas, 2008.

PEÑA DE MORAES, Guilherme. Curso de Direito Constitucional. 4. ed. São Paulo: Atlas, 2012.

QUEIROZ, Luís Cesar Souza de Queiroz. Mandado de injunção e inconstitucionalidade por omissão. Revista de Direito Constitucional e Internacional, vol. 23/1998 | p. 197 - 237 |Abr./Jun., 1998.

SILVA, José Afonso. Aplicabilidade das normas constitucionais. 3. ed. São Paulo: Malheiros, 1998.

SILVA, Tagore Trajano de Almeida Silva. Eficácia concretista das decisões do STF em sede de ação direta de inconstitucionalidade por omissão: possibilidade do Judiciário suprir as omissões do Estado. Revista de Direito Brasileira | vol. 2/2012 | p. 193 - 228 | Jan./Jun., 2012.

SILVA, Virgílio Afonso. Direitos Fundamentais: conteúdo essencial, restrições e eficácia. 2 ed. São Paulo: Malheiros, 2010.

O Conteúdo Essencial dos Direitos Fundamentais e a Eficácia das Normas Constitucionais. Revista de Direito do Estado, n. 4, 2006, p. 23-51. 
Os Direitos Fundamentais e a Lei: a constituição brasileira tem um sistema de reserva legal? In: SOUZA NETO, Cláudio Pereira de e outros (org.). Vinte Anos da Constituição Federal de 1988. Rio de Janeiro: Lumen Juris, 2009.

SLAIBI FILHO, Nagib. Direito Constitucional. 2. ed. Rio de Janeiro: Forense, 2006 SUNDFELD, Carlos Ari. Mandado de Injunção. Doutrinas Essenciais de Direito Constitucional, vol. 5 | p. 581 - 592 | Mai. 2011. 